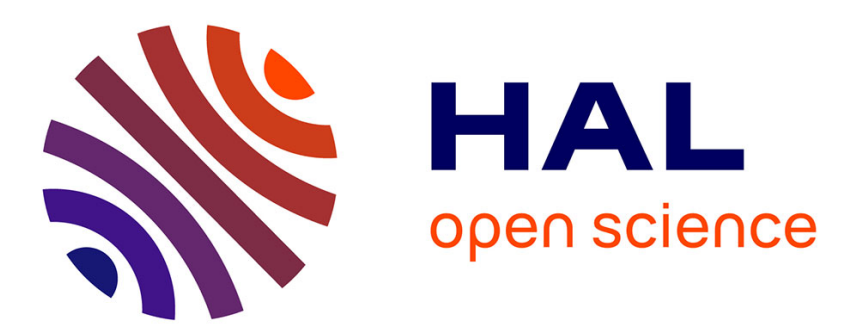

\title{
MICROWAVE PROPERTIES OF ARC PLASMA SPRAYED LITHIUM FERRITE
}

\author{
R. Kaelberer, G. White, C. Patton
}

\section{To cite this version:}

R. Kaelberer, G. White, C. Patton. MICROWAVE PROPERTIES OF ARC PLASMA SPRAYED LITHIUM FERRITE. Journal de Physique Colloques, 1977, 38 (C1), pp.C1-255-C1-259. 10.1051/jphyscol:1977154 . jpa-00217014

\section{HAL Id: jpa-00217014 https://hal.science/jpa-00217014}

Submitted on 1 Jan 1977

HAL is a multi-disciplinary open access archive for the deposit and dissemination of scientific research documents, whether they are published or not. The documents may come from teaching and research institutions in France or abroad, or from public or private research centers.
L'archive ouverte pluridisciplinaire HAL, est destinée au dépôt et à la diffusion de documents scientifiques de niveau recherche, publiés ou non, émanant des établissements d'enseignement et de recherche français ou étrangers, des laboratoires publics ou privés. 


\title{
MICROWAVE PROPERTIES OF ARC PLASMA SPRAYED LITHIUM FERRITE *
}

\author{
R. E. KAELBERER, G. O. WHITE and C. E. PATTON
}

Department of Physics Colorado State University, Fort Collins, Colorado, 80523, U. S. A.

\begin{abstract}
Résumé. - On a obtenu des données micro-ondes fondamentales en bande $\mathrm{X}$ sur la largeur de raie effective $\left(\Delta H_{\text {ert }}\right)$ et la largeur de raie des ondes de spin en pompage parallèle $\left(\Delta H_{\mathrm{k}}\right)$ pour une série de ferrites polycristallins de lithium (aimantation $1200 \mathrm{G}$ ) destinés à des déphaseurs et fabriqués par pulvérisation en plasma d'arc (matériaux APS). A titre de comparaison les mêrmes mesures ont été aussi effectuées sur un ferrite de lithium préparé de façon classique. Aux champs faibles et élevés, en dehors du manifold d'ondes de spin, tous les matériaux présentent une largeur de raie effective comparable inférieure à 10 Oe. A l'intérieur du manifold les matériaux APS avec des additions de $\mathrm{Zn}$ ont un pic de $\Delta H_{\text {eft }}$ plus faible que ceux sans addition; toutefois le pic de largeur de raie effective pour tous les matériaux APS est plus large que celui du matériau classique. Les additions de $\mathrm{Zn}$ ont un effet opposé sur les résultats à forte puissance ; $\Delta H_{\mathrm{k}}$ est plus large pour les matériaux contenant du $\mathrm{Zn}$.
\end{abstract}

\begin{abstract}
Fundamental microwave data on the X-band effective linewidth $\left(\Delta H_{\text {eff }}\right)$ and parallel pump spin-wave linewidth $\left(\Delta H_{\mathrm{k}}\right)$ have been obtained for a series of arc plasma sprayed (APS) polycrystalline, $1200 \mathrm{G}$, lithium ferrite phase shifter materials. For comparison, these measurements were also performed for a conventionally sintered lithium ferrite material. At low and high fields, outside the manifold region, all materials had comparable $\Delta H_{\text {efr }}<10$ Oe. Within the manifold region, APS materials with $\mathrm{Zn}$ additions had a lower peak $\Delta H_{\text {ef }}$ than those without, although the peak effective linewidths for all the APS materials were larger than the value measured for the conventional material. Zinc additions had an opposite effect on the high power data where $\Delta H_{\mathrm{k}}$ was larger for APS materials with $\mathrm{Zn}$ additions.
\end{abstract}

1. Introduction. - Recent interest in the use of arc plasma sprayed (APS) lithium ferrite materials for phased array radar applications [1] has shown the need for a study of the basic microwave properties of these APS materials. The APS process is an economical and promising method for the preparation of ferrite materials for device applications. Two important considerations are : (1) the insertion loss of the device, (2) the microwave power handling capability of the material.

Prototype phase shifters have been produced and evaluated in device configurations [1]. However, very little basic microwave data have been reported for these materials. The present paper reports on measurements of (1) effective linewidth $\left(\Delta H_{\text {eff }}\right)$ versus static field at $10 \mathrm{GHz}$ and (2) spin-wave linewidth $\left(\Delta H_{\mathrm{k}}\right)$ versus field over the parallel pumping region $(0-1.7 \mathrm{kOe})$ at $9.2 \mathrm{GHz}$. These basic data represent the first such comprehensive measurements on arc-plasma sprayed lithium ferrite materials.

The effective linewidth concept was introduced to provide a meaningful loss parameter for ferrite materials biased at fields outside of the resonance region [2]. Phase shifters generally operate at remanence magnetization. Thus, the low field $\Delta H_{\text {eff }}$ is the relevant loss parameter. The region around resonance (manifold region) is usually characterized by a large increase in

\footnotetext{
* Work supported by ARO Contract \# CO4-75-6-0010.
}

$\Delta H_{\text {cff }}$ due to anisotropy and/or porosity related inhomogeneous broadening or two-magnon scattering [3]. The field dependence of $\Delta H_{\text {eff }}$ in this region is related to the ferrite microstructure [4]. At high field $\Delta H_{\text {eff }}$ is generally taken as a measure of the intrinsic losses in the absence of any two-magnon scattering or inhomogeneous broadening. Room temperature results at $9.9 \mathrm{GHz}$ are reported here for all three field regions.

The spin-wave linewidth is the relaxation rate of spin-wave modes, expressed in linewidth units, which are parametrically pumped when the microwave field amplitude $(h)$ exceeds some critical value $h_{\text {crit }}$. For $h>h_{\text {crit }}$, the material losses and the related insertion loss increase substantially over the values below $h_{\text {crit }}$. Therefore, $h_{\text {crit }}$ is a quantitative measure of the power handling capability of the material. Both $h_{\text {crit }}$ and the derived spin-wave linewidth, $\Delta H_{\mathrm{k}}$, exhibit a characteristic field dependence. Results on $h_{\text {crit }}$ versus static field, the so-called butterfly curve for parallel pumping, have been obtained at room temperature and $8.9 \mathrm{GHz}$. These data were used to calculate the wave number dependence of $\Delta H_{\mathrm{k}}$. This dependence is related to the ferrite microstructure and to grain size effects in particular.

2. Ferrite materials. - The arc plasma spray (APS) materials were fabricated and supplied by R. W. Babbitt and coworkers [5]. They consisted of long, rectangular ferrite toroids sprayed directly on dielectric 
cores. The ferrite material was machined to a thickness of about $1.5 \mathrm{~mm}$. To obtain spherical samples for the basic microwave measurements, cubes of ferrite material were cut from the toroids and ground into spheres of 1.0-1.4 mm diameter by a two-pipe lapidary method. The toroids were initially sprayed from two types of powders, Ampex 1202 powder $\left(\mathrm{Li}_{0.79} \mathrm{Fe}_{1.63} \mathrm{Ti}_{0.57} \mathrm{Mn}_{0.03} \mathrm{O}_{4}\right)$ and Ampex 1200 powder (composition similar to 1202 but with $\mathrm{Zn}$ additions). Both powders have saturation magnetizations $\left(4 \pi M_{s}\right)$ on the order of $1200 \mathrm{G}$. For comparison, samples were also cut and ground from a conventionally sintered $1200 \mathrm{G}$ substituted lithium ferrite material, Trans-Tech L-27-J [6].

Table I lists the samples, powder preparation, grain size, and measured $4 \pi M_{\mathrm{s}}$ for the materials studied.

\section{TABLE I}

Sample composition and microstructure for the lithium ferrite materials of this study

$\begin{array}{cccc}\begin{array}{c}\text { Sample } \\ \text { code number }\end{array} & \begin{array}{c}\text { Sample preparation } \\ \text { Average grain } \\ \text { size }(\mu)\end{array} & \begin{array}{c}4 \pi M_{s} \\ (\mathrm{G})\end{array} \\ \begin{array}{c}\text { APS } \\ \text { C-L-113 }\end{array} & \begin{array}{c}\text { Ampex 1202 powder } \\ \text { fully reacted }\end{array} & \overline{7.4} & 1240 \\ \text { APS } & \begin{array}{c}\text { Ampex 1202 powder } \\ \text { f-L-122 }\end{array} & 4.7 & 1200 \\ \text { APS } & \begin{array}{c}\text { Ampex 1202 powder } \\ \text { spray dried }\end{array} & 11.1 & 1140 \\ \text { C-L-163 } & \begin{array}{c}\text { Ampex 1202 powder } \\ \text { APS }\end{array} & - & 1210 \\ \text { C-L-130 } & \begin{array}{c}\text { fully reacted (no an- } \\ \text { neal) }\end{array} & & \\ \text { APS } & \begin{array}{c}\text { Ampex 1200 powder } \\ \text { partially reacted } \\ \text { C-L-012 }\end{array} & - & 1110 \\ \text { APS } & \begin{array}{c}\text { Ampex 1200 powder } \\ \text { spray dried (with Zn }\end{array} & 7.3 & 1220 \\ \text { C-L-077 } & \begin{array}{l}\text { addition) } \\ \text { Trans-Tech } \\ \text { Conventional firing }\end{array} & \text { large } & 1240 \\ & & & \end{array}$

The values of $4 \pi M_{\mathrm{s}}$ were determined at $8 \mathrm{kOe}$ applied field by standard vibrating sample magnetometry. The $4 \pi M_{\mathrm{s}}$ values are accurate to $\pm 4 \%$. The small error is due to an uncertainty in the sample volume determinations on the small spheres. The average grain sizes were estimated from electron microscopy photographs [7].

3. Effective linewidth. - The experimental technique used to measure the effective linewidth is an improved version of that reported by Patton and Kohane [8]. The sample is placed in a transmission cavity and the microwave susceptibility is measured as a function of static external magnetic field. The changes in cavity $Q$ and resonant frequency yield the complex microwave susceptibility of the sample. Improvements in sensitivity were achieved by using a high stability counter [9] to directly measure the klystron frequency to within $500 \mathrm{~Hz}$ at $10 \mathrm{GHz}$. The frequency drift of the cavity due to temperature changes around room temperature ambient was reduced when necessary with a temperature stabilized water jacket around the cavity. The cavity temperature could be maintained constant within $\pm 0.04{ }^{\circ} \mathrm{C}$ at $8^{\circ} \mathrm{C}$.

To measure the effective linewidth in the manifold region [10], from about $3 \mathrm{kOe}$ to $4.5 \mathrm{kOe}$, a $\mathrm{TE}_{102}$ rectangular cavity with a relatively low $Q$ of about 1700 was used. Data were taken at $9.9 \mathrm{GHz}$ and room temperature. Temperature stabilization of the cavity was not necessary. Representative data are shown in figure 1. The field dependence of $\dot{\Delta} H_{\text {eff }}$ for all the

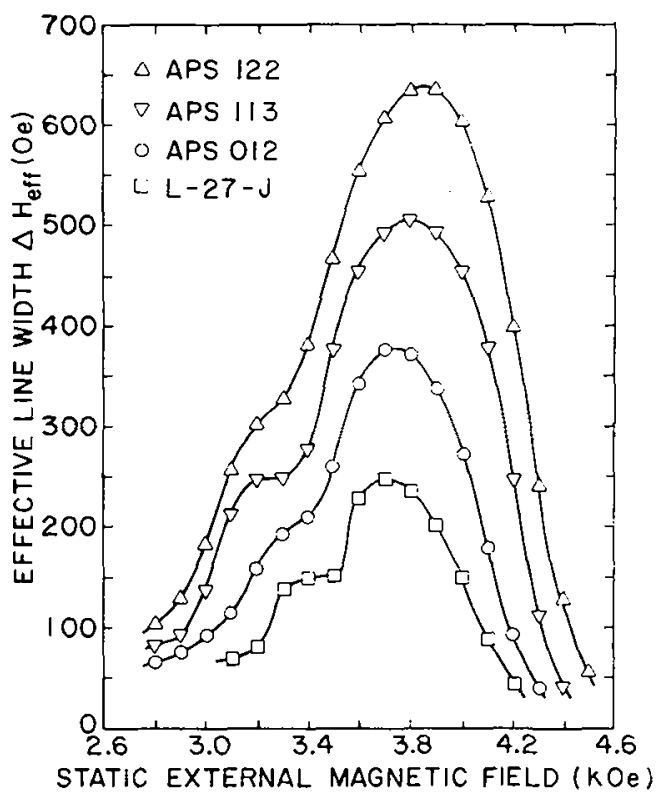

FiG. 1. - Effective line-width as a function of static external magnetic field in the manifold region for the lithium ferrite materials.

samples is similar to that for dense Ca-V substituted YIG with large magnetocrystalline anisotropy and porous YIG with relatively high porosities ( $>5 \%$ ) [4]. The APS materials exhibit larger losses than the conventional fired L-27-J, presumably an indication of the increased porosity of materials fabricated by the APS method.

Some correlation with composition and grain size can also be seen in the tabulation of the peak $\Delta H_{\text {eff }}$ values given in table $I I$. The samples are listed in order of decreasing $\Delta H_{\text {eff }}$. The four samples with the largest $\Delta H_{\text {eff }}$ are from the Ampex 1202 powder with no $\mathrm{Zn}$ additions. Of this group, the largest value of $\Delta H_{\text {eff }}$ was measured for the C-L-122 sample which has the smallest average grain size. The two samples, C-L-012 and C-L-077, sprayed from Ampex 1200 powder with $\mathrm{Zn}$ additions, have lower peak $\Delta H_{\text {eff }}$ values. This may be related to a reduction in crystalline anisotropy reported for conventional $\mathrm{Zn}$ substituted $\mathrm{Li}$ ferrite [11]. The smallest $\Delta H_{\text {cff }}$ was found for the conventional, commercially prepared Trans-Tech L- 


\section{TABLE II}

Peak effective linewidth measured in the manifold region, sample composition and average grain size for the lithium ferrite materials.

\begin{tabular}{|c|c|c|c|}
\hline Sample & $\begin{array}{c}\text { Peak } \\
\mathrm{H}_{\mathrm{eff}}(\mathrm{Oe})\end{array}$ & Material & $\begin{array}{l}\text { Average grain } \\
\text { size }(\mu) \\
-\end{array}$ \\
\hline C-L-122 & 630 & APS 1202 & 4.7 \\
\hline C-L-163 & 520 & APS 1202 & 11.1 \\
\hline$C-L-130$ & 510 & APS 1202 & - \\
\hline C-L-113 & 500 & APS 1202 & 7.4 \\
\hline C-L-012 & 370 & $\begin{array}{c}\text { APS } 1200 \\
\text { (Zn addition) }\end{array}$ & - \\
\hline C-L-077 & 330 & $\begin{array}{c}\text { APS } 1200 \\
\text { (Zn addition) }\end{array}$ & 7.3 \\
\hline L-27-J & 250 & Conventional & large \\
\hline
\end{tabular}

27-J. Although none of the APS materials have effective linewidths as low as the conventionally prepared material, those with $\mathrm{Zn}$ additions do appear to have reduced effective linewidths in the manifold region. Although the data are somewhat limited and not completely consistent, it also appears that a small $\Delta H_{\text {eff }}$ in the manifold region is related to large average grain size.

Outside the manifold region, at fields below $3 \mathrm{kOe}$ or above $4.5 \mathrm{kOe}$, two-magnon scattering and inhomogeneous broadening related to low $k$ spin-waves are absent [3]. The relaxation rate is considerably reduced, compared to the values in the manifold region. Very accurate measurements of cavity parameters are necessary to determine the effective linewidth. For these offresonance $\Delta H_{\text {efr }}$ determinations, a $\mathrm{TE}_{011}$ cylindrical cavity with a high $Q(20,500)$ was used. Measurements were made at $9.8 \mathrm{GHz}$ and the cavity temperature stabilized at $8{ }^{\circ} \mathrm{C} \pm 0.04^{\circ} \mathrm{C}$.

Representative data outside the manifold region are shown in figure 2. These $\Delta H_{\text {eff }}$ values are smaller than the values measured in the manifold region (Fig. 1) by a factor of 50. For these off-resonance $\Delta H_{\text {cff }}$ data, there appears to be no consistent correlation between APS

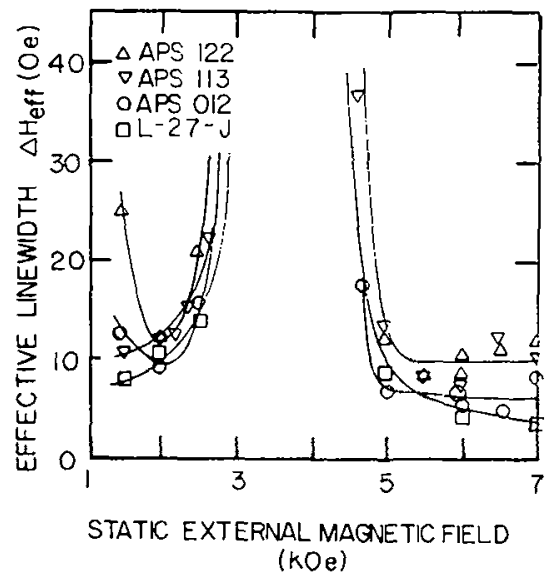

FIG. 2. - Effective linewidth as a function of static external magnetic field outside the manifold region for the lithium ferrite materials. parameters and the losses. The effective linewidths at high field for the APS materials are about 5-10 Oe. The conventionally prepared L-27-J has a high field $\Delta H_{\text {eff }}$ of about 4 Oe. These values are quite comparable. For fields around $2 \mathrm{kOe}$, the $\Delta H_{\mathrm{eff}}$ for all samples is slightly higher than at high field, on the order of $10 \mathrm{Oe}$. Precise measurements are precluded by the large inhomogeneous broadening contributions which expand the manifold region, and by experimental problems at low fields $(<2 \mathrm{kOe})$ due to low susceptibilities and small samples.

It is clear, however, that the relevant linewidth parameter for the APS materials in phase shifter applications is on the order of 5-10 Oe. This value is comparable to the low-field $\Delta H_{\text {eff }}$ for conventionally prepared materials.

4. Spin-wave linewidth. - Spin-wave thresholds $\left(h_{\text {erit }}\right)$ and linewidths $\left(\Delta H_{\mathrm{k}}\right)$ for the various lithium ferrite materials were determined from the microwave field dependence of the parallel pump susceptibility. The signal source was a $2 \mathrm{~J} 51$ tunable X-band magnetron driven by a modified MIT Model 3 hard tube modulator [12]. Microwave pulses $3 \mu \mathrm{s}$ long at $8.96 \mathrm{GHz}$, with a $200 \mathrm{~Hz}$ repetition rate were used in conjunction with a rectangular $\mathrm{TE}_{101}$ reflection cavity. Standard microwave techniques were used to determine the negative, imaginary part of the sample susceptibility $\left(\chi^{\prime \prime}\right)$ as a function of microwave field amplitude $h$. The threshold field $h_{\text {crit }}$ was estimated from graphs of $\chi^{\prime \prime}$ versus $h$.

The microwave threshold field $\left(h_{\text {crii }}\right)$ for parallel pump spin-wave instability is shown as a function of static applied field in figure 3. Here samples C-L-122

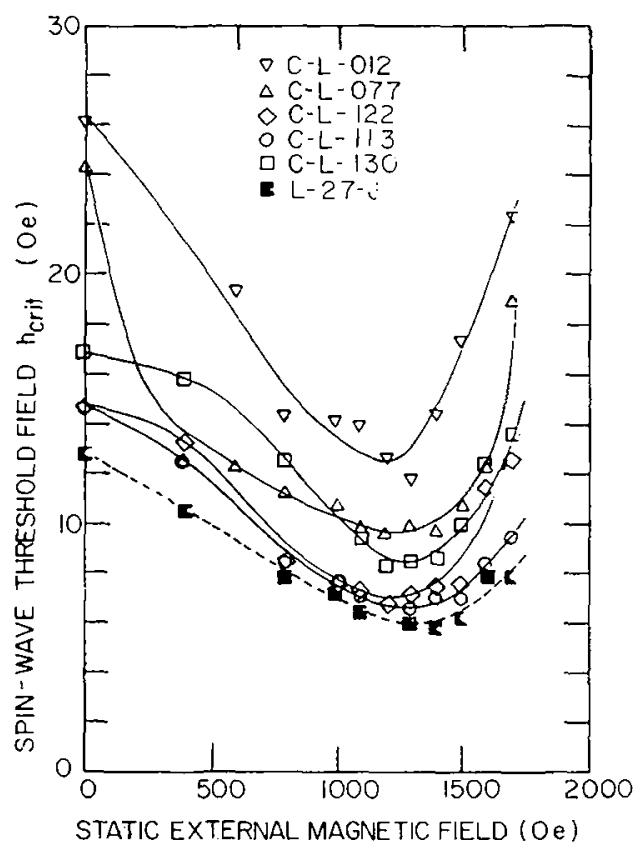

FIG. 3. - Spin-wave threshold field as a function of static external magnetic field for the lithium ferrite materials. 
and C-L-113, sprayed from Ampex 1202 powder and annealed, exhibit values of $h_{\text {cric }}$ only slightly higher than those for the commercial Trans-Tech L-27-J material. The C-L-130 sample, sprayed from 1202 powder but not annealed, has significantly higher values of $h_{\text {crit }}$. The C-L-012 and C-L-077 samples were sprayed from Ampex 1200 powder which contains a small amount of $\mathrm{Zn}$ (approximately $0.05 \mathrm{Zn}$ atoms per formula unit). It is to be noted that the magnetization of sample C-L-012 may be quite non-uniform [13]. This nonuniform $4 \pi M_{\mathrm{s}}$ is a likely cause of the large microwave threshold field in this sample, compared to the C-L-077. It is clear, however, that both 1200 powder samples exhibit higher thresholds than those of the 1202 powder samples. The following conclusions are suggested by the data of figure 3. (1) The results for the 1202 powder samples (C-L-113, C-L-122, C-L-130) indicate that the APS process can produce a significant increase in $h_{\text {crit }}$, most of which is lost upon annealing [1]. (2) Comparison of the 1200 powder samples (C-L-012, C-L-077) with the 1202 powder samples (C-L-113, C-L-122, C-L-130) shows that $\mathrm{Zn}$ additions increase the microwave power capability for APS materials, as has been noted for conventionaly sintered ferrites [11]. (3) An inhomogeneous magnetization, which can be produced by the APS process as for C-L-012, may be reflected in large apparent $h_{\text {cri }}$ values.

The wave number dependence of the spin-wave linewidth $\left(\Delta H_{\mathrm{k}}\right)$ may be obtained from the SuhlSchlömann spin-wave instability theory $[14,15]$ and the butterfly curve data of figure 3 [16]. These results are shown in figure 4 . The sample to sample

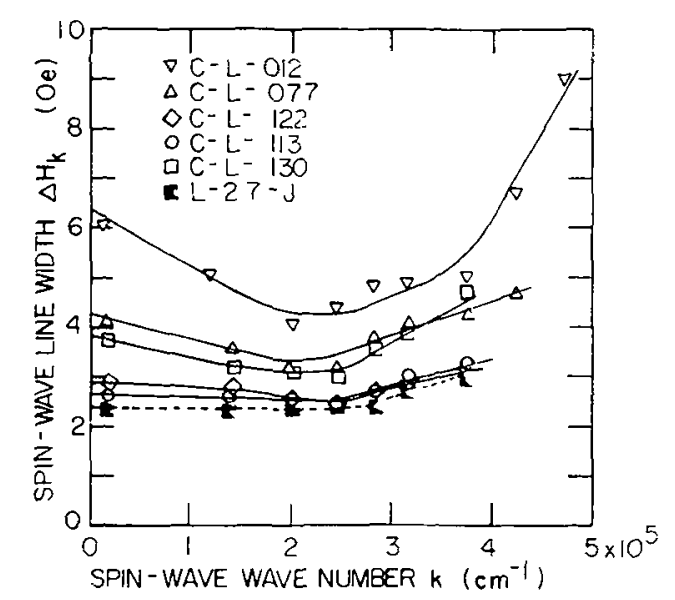

FIo. 4. - Spin-wave line-width as a function of spin-wave numbers for the lithium ferrite materials. variation in $\Delta H_{\mathrm{k}}$ is qualitatively similar to the variation in $h_{\text {crit }}$, with $\Delta H_{\mathrm{k}}(k \rightarrow 0)$ values ranging from $2.6 \mathrm{Oe}$ for the conventionally sintered L-27-J, to $6 \mathrm{Oe}$ for the $\mathrm{Zn}$ doped APS C-L-012.

Of fundamental interest is the $\Delta H_{\mathrm{k}}$ versus $k$ behaviour summarized in figure 4. Below $k \approx 2 \times 10^{5} \mathrm{~cm}^{-1}, \Delta H_{\mathrm{k}}$ is a decreasing function of $k$. Above $k \approx 2 \times 10^{5} \mathrm{~cm}^{-1}, \Delta H_{\mathrm{k}}$ is an increasing function of $k$. This general behaviour is qualitatively similar to the behaviour for fine grain and porous YIG $[17,18]$. In YIG, the inverse $k$-dependence of $\Delta H_{\mathrm{k}}$ below $k \approx 2 \times 10^{5} \mathrm{~cm}^{-1}$ has been qualitatively related to spin-wave transit time arguments $[17,18]$. The available microstructure data on the APS materials also indicate relatively small grains. Therefore, it is likely that the $\Delta H_{\mathrm{k}}$ versus $k$ dependence in figure 4 for the APS materials is related to grain size effects.

5. Discussion. - The large values of $\Delta H_{\text {eff }}$, up to $650 \mathrm{Oe}$, in the manifold region are clearly related to the porosity and microstructure inherent in the APS process. The values are reduced by the addition of $\mathrm{Zn}$. At low field $(\sim 2 \mathrm{Oe})$ or above $5 \mathrm{kOe}$, the effective linewidths of the APS materials are less than $10 \mathrm{Oe}$, comparable to those of conventionally prepared materials. The variations observed from sample to sample show no clear microstructure correlations. The high power data show that $\mathrm{Zn}$ additions increase $h_{\text {crit }}$ and $\Delta H_{\mathrm{k}}$, opposite to the effect of $\mathrm{Zn}$ on $\Delta H_{\mathrm{eff}}$ in the manifold region. This result is quite peculiar. The $\Delta H_{\text {eff }}$ in the manifold region and the high $h_{\text {crit }}$ values must both be microstructure related. It is perplexing that a microstructure effect, which increases $\Delta H_{\text {eff }}$, can cause a decrease in $\Delta H_{\mathrm{k}}$. Some clues to this behaviour may be inferred from previous work on the effect of $\mathrm{Zn}$. As previously mentioned, Baba, et al. [11] report that $\mathrm{Zn}$ reduces the magnetocrystalline anisotropy. This may be the cause of the reduction in $\Delta H_{\text {eff }}$. West and Blankenship [19] report that $\mathrm{Zn}$ can increase porosity in hot pressed Li-ferrite. This may be related to the $\Delta H_{\mathrm{k}}$ increase.

The most important practical observations are : (1) zinc substitution increases $\Delta H_{\mathrm{k}}$, while decreasing $\Delta H_{\text {crf }}$ in the manifold region ; (2) the off-resonance loss properties are comparable to the losses in conventional materials ; (3) the high power capability is the same or better than that of conventional materials. These observations in combination with the economic advantages of the APS process indicate the utility of these lithium ferrite materials for phase shifter applications.

\section{References}

[1] BABbitT, R. W., IEEE Trans. Mag. MAG-11 (1975) 1253.

[2] Kohane, T. and Schlömann, E., J. Appl. Phys.39(1968) 720.

[3] Patton C. E., IEEE Trans. Mag. MAG-8 (1972) 433.

[4] Patron, C. E., Phys. Rev. 179 (1969) 352.
[5] APS materials supplied by R. W. Babbitt, Army Electronic Command, Fort Monmouth, New Jersey, U.S. A. [6] Trans-Tech L-27-J lithium ferrite supplied by R. West, Trans-Tech, Inc., Gaithersburg, Maryland, U.S. A. 
[7] Data on microstructure provided by A. Tauber, Army Electronic Command, Fort Monmouth, New Jersey, U. S. A.

[8] Patron, C. E. and Kohane, T., Rev. Sci. Instr. 43 (1972) 76.

[9] Model 5340A Hewlett Packard frequency counter.

[10] The manifold region is defined as the field region in which the uniform precession is degenerate with low wave number spin-wave states.

[11] Baba, P. D., Aroentina, G. M., Courtney, W. E., Dronne, G. F., and Temme, D. H., IEEE Trans. Mag. MAG-8 (1972) 83.

[12] The MIT Model 3 pulser, which is capable of delivering $144 \mathrm{KW}$ pulses to the magnetron, is inexpensively available surplus for $\$ 50-\$ 300$. Its modification will be discussed in a future publication.

[13] TAuBRr, A., private communication.
[14] Suhl, H., J. Phys. Chem. Solids 1 (1957) 209.

[15] SchlömanN, E., Raytheon technical Report R-48, October 1959.

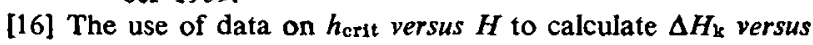
wavenumber $k$ requires a numerical value for the exchange parameter $D$. In order to obtain $\Delta H_{\mathrm{k}}$ versus $k$, the YIG value (see Ref. [18]) $D=5 \times 10^{9} \mathrm{Oe} \mathrm{cm}^{2}$ has been used. This is a reasonable approximation because the Curie temperatures are the same to within about $15 \%$. Any error in $k$, however, is probably less than this, since $k$ varies as $\sqrt{D}$.

[17] Patton, C. E., J. Appl. Phys. 41 (1970) 1637.

[18] Patton, C. E., Proc. Intl. Conf. on Ferrites, Kyoto, Japan (U. of Tokyo Press, Tokyo) (1970) p. 524.

[19] West, R. G., and Blankenship, A. C., J. Amer. Ceram. Soc. 50 (1967) 343. 